\title{
Identification of acute vaccine-preventable hepatitis in individuals with chronic hepatitis in British Columbia between 1991 and 2007
}

\author{
Lily Fang $\mathrm{MHSc}^{1,2}$, Amanda $\mathrm{Yu} \mathrm{BSc}^{1,3}$, Jane A Buxton MBBS $\mathrm{MHSc}^{1,3}$
}

L Fang, A Yu, JA Buxton. Identification of acute vaccinepreventable hepatitis in individuals with chronic hepatitis in British Columbia between 1991 and 2007. Can J Infect Dis Med Microbiol 2011;22(1):10-14.

BACKGROUND: In British Columbia (BC), hepatitis A virus (HAV) and hepatitis $B$ virus (HBV) vaccines are provincially funded for persons with chronic hepatitis infections.

PURPOSE: To assess the effectiveness of $\mathrm{BC}$ public health follow-up of HBV and hepatitis $\mathrm{C}$ virus (HCV) cases and immunization policy by determining the number of vaccine-preventable acute hepatitis infections reported following a chronic HBV or HCV diagnosis, by examining demographic characteristics and by observing temporal trends.

METHODS: All newly identified cases of HAV, HBV and HCV between 1991 and October 2007 were extracted from the BC integrated Public Health Information System and linked to ascertain cases of hepatitis suprainfection.

RESULTS: Between 1991 and October 2007, 30 BC residents with chronic HBV and 104 with HCV were subsequently diagnosed with HAV. Acute HBV was identified in 162 persons previously diagnosed with HCV. Significantly more men than women developed hepatitis suprainfection $(P<0.0001)$, but women were of a younger age when they were diagnosed with HAV $(\mathrm{P}=0.02)$ and acute HBV $(\mathrm{P}=0.0002)$. HAV suprainfection cases among those with HCV peaked in 1998 at 33 cases and declined to zero cases in 2007. In comparison, HBV suprainfection among individuals with chronic HCV peaked in 1996 at 26 cases and declined to two cases in 2007.

DISCUSSION: Cases of HAV and acute HBV have declined among HCV-infected individuals. However, despite the availability of publicly funded vaccines for high-risk groups, a substantial number of acute HBV infections post-HCV identification are still identified, indicating that follow-up and vaccination coverage should be improved in these populations.

Key Words: British Columbia; Hepatitis A; Hepatitis B; Hepatitis C
Le dépistage de l'hépatite aigue évitable par la vaccination chez des personnes de la ColombieBritannique atteintes d'une hépatite chronique, entre 1991 et 2007

HISTORIQUE : En Colombie-Britannique (C.-B.), les personnes atteintes d'une infection par l'hépatite chronique peuvent recevoir les vaccins contre le virus de l'hépatite $A$ (VHA) et le virus de l'hépatite $B$ (VHB) financés par la province.

OBJECTIF : Évaluer l'efficacité du suivi et des politiques de vaccination de la santé publique de la C.-B. à l'égard des cas de VHB et de virus de l'hépatite $\mathrm{C}(\mathrm{VHC})$ en déterminant le nombre d'infections aiguës par l'hépatite évitables par la vaccination déclarées après un diagnostic de VHB ou de VHC chronique, par l'examen des caractéristiques démographiques et l'observation des tendances dans le temps. MÉTHODOLOGIE : Les chercheurs ont extrait tous les cas nouvellement diagnostiqués de VHA, de VHB et de VHC du Système d'information en santé publique de la C.-B. entre 1991 et octobre 2007 et les ont liés pour déterminer les cas de suprainfection par l'hépatite. RÉSULTATS : Entre 1991 et octobre 2007, 30 habitants de la C.-B. déjà atteints de $\mathrm{VHB}$ chronique et 104 déjà atteints $\mathrm{VHC}$ ont reçu un diagnostic de VHA. On a diagnostiqué un VHB chez 162 personnes ayant reçu un diagnostic préalable de VHC. Beaucoup plus d'hommes que de femmes ont contracté un suprainfection par l'hépatite $(\mathrm{P}<0,0001)$, mais les femmes étaient plus jeunes au moment de leur diagnostic de VHA $(\mathrm{P}=0,02)$ et de VHB aigu $(\mathrm{P}=0,0002)$. Chez les personnes atteintes de VHC, les suprainfections par le VHA ont atteint un sommet en 1998, avec 33 cas, et ont chuté à zéro cas en 2007. En comparaison, les suprainfections par le VHB chez les personnes ayant un VHC ont chronique a atteint un sommet en 1996, avec 26 cas, et ont fléchi à deux cas en 2007. EXPOSÉ : Les cas de VHA et de VHB aigu ont diminué chez les personnes infectées par le VHC. Cependant, même si les groupes à haut risque peuvent recevoir les vaccins financés par le gouvernement, un nombre important d'infections aiguës par le VHB est tout de même diagnostiqué après un diagnostic de VHC. Ainsi, il faudrait améliorer le suivi et la couverture vaccinale au sein de ces populations.

infection has no chronic carrier state and confers lifelong immunity (2). The development of chronic HBV following acute HBV infection is inversely associated with age, with a $90 \%$ risk of chronic infection among HBV-infected infants and 1\% to 5\% among adults (3). People with chronic viral hepatitis who become acutely infected (suprainfected) with HAV or HBV are at an increased risk of liver failure (12); chronic HBV and HCV coinfection is associated with poorer outcomes and an accelerated progression of liver disease $(7,13-15)$.

Between 1991 and October 2007, 33,250 chronic HBV and 59,080 HCV cases were reported in British Columbia (BC). Both acute HAV and HBV are vaccine preventable, and these vaccines are provincially funded for certain susceptible populations including out sequelae; case fatality is usually low $(0.1 \%$ to $0.3 \%)$, but may higher in older persons and those with comorbidities (3). HAV

${ }^{1}$ BC Centre for Disease Control, Vancouver, British Columbia; ${ }^{2}$ Department of Public Health Sciences, University of Toronto, Toronto, Ontario; ${ }^{3}$ School of Population and Public Health, University of British Columbia, Vancouver, British Columbia

Correspondence: Dr Jane A Buxton, BC Centre for Disease Control, 655 West 12th Avenue, Vancouver, British Columbia V5Z 4R4.

Telephone 604-707-2573, fax 604-707-2516, e-mail Jane.buxton@bccdc.ca 
persons with $\mathrm{HCV}$; HAV vaccine is also available for persons with chronic HBV. To assess the effectiveness of BC immunization policy and public health follow-up of HBV and HCV cases, we identified vaccine-preventable acute hepatitis infections following a diagnosis of chronic HBV or HCV, examined demographic characteristics at the time of virus identification and observed temporal trends.

\section{METHODS}

Data source

Among BC residents, all newly identified cases of HAV, HBV and $\mathrm{HCV}$ that have not been previously reported elsewhere in Canada are recorded by $\mathrm{BC}$ regional health authorities (HAs) into the $\mathrm{BC}$ integrated Public Health Information System (iPHIS). Cases of acute HAV in persons previously reported as being chronically infected with $\mathrm{HBV}$ or HCV, and acute HBV in persons previously reported with $\mathrm{HCV}$ in the iPHIS were identified. Demographic information available in the iPHIS included age, sex, date of each hepatitis virus identification, and residence at time of virus identification according to HA and health service delivery area.

\section{Case identification and data management}

Nominal data and personal health numbers were used to link cases of acute HBV and HAV reported between 1991 and October 2007 to previously reported cases of chronic HBV and HCV. If individuals had more than one HAV-, HBV- or HCV-positive result, the date of the first positive result was considered to be the date of identification. Acute HAV is diagnosed by positive immunoglobulin $\mathrm{M}$ antibody to HAV with a compatible clinical history or exposure. HBV is considered to be acute if a case is positive for hepatitis B surface antigen and immunoglobulin $\mathrm{M}$ antibody to hepatitis $\mathrm{B}$ core antigen, or if the individual tested positive for hepatitis B surface antigen and cleared it within six months in the context of compatible clinical history or probable exposure. If reported HBV infection was not classified as acute, it was considered to be chronic. Individuals with positive reports of acute hepatitis within 14 days of chronic hepatitis identification were excluded from the analyses to account for delays in laboratory testing and reporting.

On completion of data linkages using a computer algorithm, personal identifiers (first and last name and personal health numbers) were deleted, and the anonymized data were subsequently analyzed. Data were cleaned of cases with probable data entry errors. Because $\mathrm{BC}$ guidelines recommend that high-risk infants undergo testing one to six months after completion of HBV vaccine series (administered at zero, one and six months after birth), any HBV infections identified within seven months of birth were excluded. Similarly, because infants at risk for vertical transmission of HCV should be tested at or after six weeks of age, cases reported before the age of six weeks were excluded.

The study received approval from the Behavioural Research Ethics Board of the University of British Columbia (Vancouver, BC).

\section{Statistical analyses}

Data linkages and analyses were performed using SAS version 9.1 (SAS Institute Inc, USA). To determine the identification rate of hepatitis, P.E.O.P.L.E 32 Population Estimates and Projections were obtained from BC Stats. The mean population estimate during the observation period was used to calculate the cumulative identification rate. Because data were only available until October 2007 and no seasonal variations were found, the annual identification rate for 2007 was prorated. Differences in age at hepatitis identification and time between chronic and acute hepatitis detection were examined using $t$ tests. ANOVA was used to test for differences in age at hepatitis diagnosis, and the time between chronic and acute hepatitis virus identification according to type of chronic hepatitis infection. To compare differences across sex and HAs, $\chi^{2}$ and Fisher's exact tests were used. A two-sided $\mathrm{P}<0.05$ was considered to be statistically significant.
TABLE 1

Demographic characteristics of 121 individuals residing in British Columbia between 1991 and October 2007 with chronic hepatitis who later developed acute hepatitis A virus (HAV), and 3582 individuals who were identified with HAV only

\begin{tabular}{lcc}
\hline Characteristic & HAV/chronic hepatitis & HAV only \\
\hline Sex, $\mathrm{n}$ & 121 & 3548 \\
Male & $83(68.6)$ & $2319(65.4)$ \\
Female & $38(31.4)$ & $1229(34.6)$ \\
Age (years), $\mathrm{n}$ & 116 & 3354 \\
$0-9$ & $0(0.0)$ & $333(9.9)$ \\
$10-19$ & $2(1.7)$ & $408(12.2)$ \\
$20-29$ & $34(29.3)$ & $853(25.4)$ \\
$30-39$ & $43(37.1)$ & $829(24.7)$ \\
$40-49$ & $25(21.6)$ & $468(14.0)$ \\
$50-59$ & $9(7.8)$ & $240(7.2)$ \\
60+ & $3(2.6)$ & $223(6.6)$ \\
Age at HAV diagnosis, years & $35.9(33.9-37.8)$ & $31.6(31.1-32.2)$ \\
(mean [range]) & & \\
Residence, $\mathrm{n}$ & 121 & 3582 \\
Fraser Health Authority & $41(33.9)$ & $914(25.5)$ \\
Interior Health Authority & $22(18.2)$ & $334(9.3)$ \\
Northern Health Authority & $6(5.0)$ & $184(5.1)$ \\
Vancouver Coastal Health & $42(34.7)$ & $1537(42.9)$ \\
Authority & & \\
Vancouver & $28(23.1)$ & $613(17.1)$ \\
Vancouver Island Health & $10(8.3)$ & \\
Authority & & \\
\hline Da prese &
\end{tabular}

Data presented as $n(\%)$ unless otherwise indicated

\section{RESULTS}

Data cleaning removed a total of 90 cases; the majority were excluded to ensure temporality (ie, acute HAV or HBV diagnosis occurred after chronic hepatitis diagnosis [not before or within 14 days]). Between 1991 and October 2007, 30 BC residents with chronic HBV and 104 with HCV were subsequently reported to be infected with HAV (Table 1); of these, 13 had HAV after both chronic HBV and HCV. During this period, the overall cumulative population rate of HAV suprainfection identification was 3.1 per 100,000. In comparison, the cumulative identification rate for individuals diagnosed with HAV alone was 82.3 per 100,000 , and the mean age at diagnosis was significantly younger than the suprainfected cases -31.6 years $(95 \%$ CI 31.1 to 32.2 ) versus 35.9 years ( $95 \%$ CI 33.9 to 37.8 ).

In the same period, 162 individuals with chronic HCV were suprainfected with acute HBV (Table 2). The overall cumulative population rate of acute HBV/chronic HCV suprainfection was 4.1 per 100,000 . There were significant differences across HAs for age at acute HBV diagnosis $(\mathrm{P}=0.02)$. In particular, residents of Interior HA were significantly older than Fraser HA residents diagnosed with acute HBV (mean age 43.6 years [95\% CI 37.2 to 50.1 ] versus 34.5 years [ $95 \%$ CI 32.4 to 36.7]) (data not shown). Among BC residents diagnosed with acute HBV only, the cumulative identification rate was 39.2 per 100,000.

Most of the suprainfection burden was among individuals with chronic HCV (Figure 1). Among those who became infected with HAV, more $\mathrm{BC}$ residents were chronically infected with HCV than with HBV $(\mathrm{P}<0.0001)$. Furthermore, significantly more men than women developed hepatitis suprainfection $(\mathrm{P}<0.0001)$, and this relationship persisted for each hepatitis suprainfection. Among suprainfected $\mathrm{BC}$ residents, some sex differences persisted (Table 3 ). Women were significantly younger than men when they were diagnosed with $\operatorname{HAV}(\mathrm{P}=0.02)$ and acute HBV $(\mathrm{P}=0.0002)$ after identification of chronic hepatitis. However, there were no significant sex differences for the mean time to acute hepatitis identification after diagnosis of chronic hepatitis coinfection. 


\begin{tabular}{|c|c|c|}
\hline Characteristic & Acute HBV/chronic HCV & Acute HBV only \\
\hline Sex, n & 160 & 1538 \\
\hline Male & $112(70.0)$ & $1088(70.7)$ \\
\hline Female & $48(30.0)$ & $450(29.3)$ \\
\hline Age (years), $\mathrm{n}$ & 157 & 1366 \\
\hline $0-9$ & $0(0.0)$ & $8(0.6)$ \\
\hline 10-19 & $0(0.0)$ & $78(5.7)$ \\
\hline $20-29$ & $30(19.1)$ & $373(27.3)$ \\
\hline 30-39 & $69(44.0)$ & $408(29.9)$ \\
\hline $40-49$ & $44(28.0)$ & $264(19.3)$ \\
\hline $50-59$ & $12(7.6)$ & $130(9.5)$ \\
\hline $60+$ & $2(1.3)$ & $105(7.7)$ \\
\hline $\begin{array}{l}\text { Age at acute HBV diagnosis, } \\
\text { years (mean [range]) }\end{array}$ & $36.9(35.4-38.4)$ & $36.9(36.2-37.6)$ \\
\hline Residence, $\mathrm{n}$ & 162 & 1549 \\
\hline Fraser Health Authority & $51(31.5)$ & $414(26.7)$ \\
\hline Interior Health Authority & $14(8.6)$ & $164(10.6)$ \\
\hline Northern Health Authority & $8(4.9)$ & $70(4.5)$ \\
\hline $\begin{array}{l}\text { Vancouver Coastal Health } \\
\text { Authority }\end{array}$ & $43(26.5)$ & $630(40.7)$ \\
\hline Vancouver & $38(23.5)$ & $571(36.9)$ \\
\hline $\begin{array}{l}\text { Vancouver Island Health } \\
\text { Authority }\end{array}$ & $46(28.4)$ & $271(17.5)$ \\
\hline
\end{tabular}

Data presented as $n$ (\%) unless otherwise indicated

\section{DISCUSSION}

Between 1991 and October 2007, 121 HAV cases among individuals chronically infected with HBV or HCV, and 162 acute HBV cases among individuals chronically infected with HCV were identified in BC. Among chronic HCV cases, $0.2 \%$ were suprainfected with HAV and $0.3 \%$ were identified with acute HBV (data not shown). However, a substantial number of acute HAV and HBV cases likely go undetected and the number of acute HBV cases is underestimated. The Provincial Laboratory of Northern Alberta found that $53.1 \%$ of HCV-positive individuals had been previously infected with or immunized against HAV, and $44.3 \%$ had been infected with HBV. One-quarter had been exposed to both HAV and HBV (16). Among nonvaccinated adults 20 to 39 years of age in BC, $15.7 \%$ had been previously infected with HAV (17).

Vancouver residents accounted for 23.1\% of HAV suprainfection cases. In late 1997, an HAV outbreak among men who have sex with men (MSM) began in Vancouver, when the number of HAV cases reported at the end of the year increased by $100 \%$ compared with the previous few months (18). To address the outbreak, the Vancouver Coastal Health Authority established a mass HAV vaccination campaign for MSM (18). In 1999, an HAV outbreak occurred in Vancouver's Downtown Eastside, where residents included IDUs who have a high prevalence of $\mathrm{HCV}(5,19)$ and are at risk for both HBV and HCV through common routes of transmission. Vaccination uptake during outbreaks tends to be high (5), and HAV immunization policies have developed in response to trends in HAV infection (20); HAV vaccination has been free of cost for IDUs and MSM in BC since 1998 and 2001, respectively. Our data suggested that HAV vaccination of HCV-reactive persons has successfully reduced the number of HAV cases since its implementation. Although reported cases of HAV were declining before publicly funded immunization programs for high-risk groups, from 900 cases in 1992 to 478 cases in 2006; since

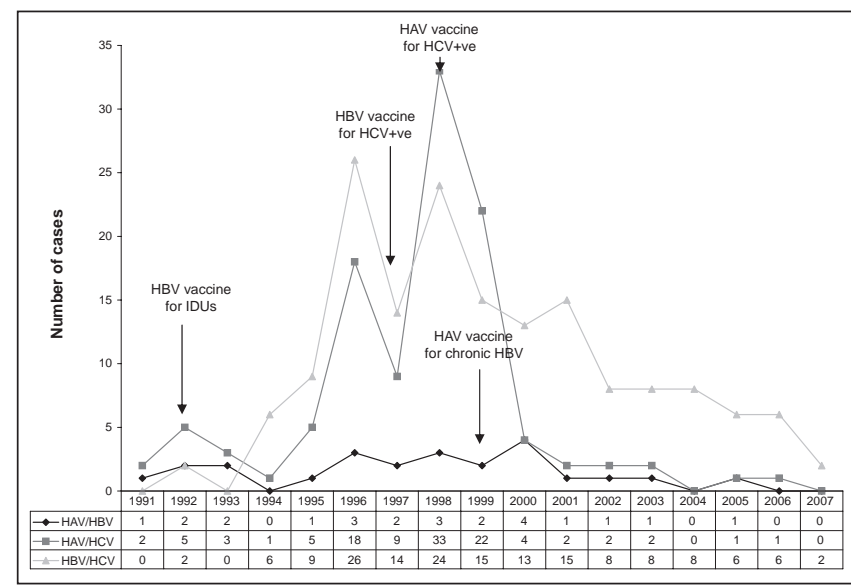

Figure 1) Number of vaccine-preventable acute hepatitis cases identified among British Columbia residents with chronic hepatitis between 1991 and 2007. Values for 2007 are prorated to account for the fact that data were only available until October. +ve Positive; HAV Hepatitis A virus; HBV Hepatitis B virus; HCV Hepatitis C virus; IDUs Injection drug users

2001, fewer than 80 cases of HAV are reported annually and, in 2007, only 41 cases were reported in BC. In a previous study of risk factors for $\mathrm{HAV}$ in four of five regional HAs in BC, cases that were identified as IDUs, and hence likely had a high prevalence of $\operatorname{HCV}(21,22)$, declined from 34 in 1998, and 23 in 1999, to zero cases in 2001 to 2004 (20). Recently, HAV infection was found to be more common among travellers to developing countries (17). Therefore, HAV infections could be decreased by targeting immunization at travellers to HAV-endemic countries.

Although the HBV vaccine was made available to IDUs in 1992 and to HCV-reactive persons in 1997, its influence on temporal trends is less apparent. In 1998, the number of acute HBV cases among persons previously diagnosed with HCV increased (which may be a consequence of increased testing), before declining after 1998. In the United States, 79\% of newly acquired HBV cases are associated with high-risk sexual activity and injection drug use (23). To increase vaccination coverage among high-risk adults, HBV vaccine could be offered in settings in which a high proportion of adults have HBV risk factors, including sexually transmitted infections/ HIV testing, and treatment centres and primary care facilities serving MSM and IDUs (21). In BC, HBV vaccine has been funded for routine vaccination among grade 6 students since 1992, and infants born on or after February 1, 2001. This translates into lower acute HBV incidence, and declines have already been noted in adolescents and young adults within 10 years after its inception, with fewer than 50 cases annually in BC since 2006 (24).

Women were significantly younger when they were diagnosed with acute hepatitis. Females are more likely to get tested (25) and, in $\mathrm{BC}$, women are routinely tested for HBV during pregnancy. However, more men develop hepatitis suprainfection because a greater number of acute HBV and HCV cases occur among males. Males are less likely to interact with the health care system (26) and, thus, may not be immunized against vaccine-preventable hepatitis following chronic hepatitis diagnosis, which may contribute to more suprainfections among males. Timeliness of vaccine administration following hepatitis diagnosis is imperative. Among individuals chronically infected with HCV, early HBV immunization is important because they may mount a better immune response to the vaccine before the onset of cirrhosis (27). Some cases of acute HBV infection in persons with $\mathrm{HCV}$ may have previously received HBV vaccine, but did not mount an adequate response; again this supports the need for early follow-up and immunization of identified individuals with HCV. 
TABLE 3

Demographic characteristics of chronic hepatitis-infected British Columbia residents identified with subsequent acute vaccine-preventable hepatitis between 1991 and October 2007 according to sex

\begin{tabular}{|c|c|c|c|c|}
\hline HAV after chronic HBV or HCV & Male & Female & Total, $\mathbf{n}$ & $\mathbf{P}$ \\
\hline Cases, n (\%) & $83(68.6)$ & $38(31.4)$ & 121 & $<0.0001$ \\
\hline Age at HAV diagnosis, years (mean [range]) & $37.7(35.2-40.2)$ & $32.0(29.3-34.6)$ & 116 & 0.02 \\
\hline Type of chronic infection, n (\%) & & & 121 & 0.03 \\
\hline $\mathrm{HAV} / \mathrm{HBV}$ & $11(9.1)$ & $0(0.0)$ & 11 & \\
\hline $\mathrm{HAV} / \mathrm{HCV}$ & $62(51.2)$ & $35(28.9)$ & 97 & \\
\hline $\mathrm{HAV} / \mathrm{HBV} / \mathrm{HCV}$ & $10(8.3)$ & $3(2.5)$ & 13 & \\
\hline Time to HAV after HBV diagnosis, days (mean [range]) & $853.0(497.2-1208.8)$ & $860.2(117.6-1838.0)$ & 30 & 1.0 \\
\hline Time to HAV after HCV diagnosis, days (mean [range]) & $701.0(536.8-865.2)$ & 701.6 (483.8-919.5) & 104 & 0.9 \\
\hline \multicolumn{5}{|l|}{ Acute HBV after chronic HCV } \\
\hline Cases, n (\%) & $112(70.0)$ & $48(30.0)$ & 160 & $<0.0001$ \\
\hline Age at acute HBV diagnosis, years (mean [range]) & $38.8(37.1-40.6)$ & $32.7(30.1-35.4)$ & 157 & 0.0002 \\
\hline $\begin{array}{l}\text { Time to acute HBV after chronic HCV diagnosis, days } \\
\text { (mean [range]) }\end{array}$ & $694.9(546.7-843.1)$ & $663.8(424.7-903.0)$ & 160 & 0.8 \\
\hline
\end{tabular}

HAV Hepatitis A virus; HBV Hepatitis B virus; HCV Hepatitis C virus

Our findings have some limitations: HAV, HBV and HCV infections are underdiagnosed and under reported. Because HAV may result in mild illness, individuals may not suspect infection and, thus, will not seek testing. Among individuals expressing symptoms of acute hepatitis, physicians will generally screen for all hepatitis viruses.

Most $\mathrm{HCV}$ tests in $\mathrm{BC}$ are performed at the $\mathrm{BC}$ Centre for Disease Control (Vancouver, BC); therefore, quality can be assured. HCVpositive sera are reflex tested for HAV and HBV immune status to determine vaccine eligibility; these results are included in the HCV report and sent to both the requesting physician and local public health. However, HBV testing occurs at hospital and private laboratories throughout the province, and determination of HAV immune status is not routinely performed in persons with HBV-positive results. In 1996 and 1997, the number of people seeking testing for hepatitis increased because they received notification to be tested due to past receipt of a blood product. HAV outbreaks were also occurring, which could explain the increase in the number of positive acute hepatitis cases identified among the chronically infected in 1998, but not the subsequent decline. The numbers presented may be a conservative

\section{REFERENCES}

1. Henning KJ, Bell E, Braun J, Barker ND. A community-wide outbreak of hepatitis A: Risk factors for infection among homosexual and bisexual men. Am J Med 1995;99:132-6

2. Wu J, Zou S, Giulivi A. Current hepatitis A status in Canada. Can J Infect Dis 2001;12:341-4.

3. Heymann DL, ed. Control of communicable diseases manual. 18th edn. Baltimore: United Book Press Inc, 2004.

4. Chudy M, Budek I, Keller-Stanislawski B, et al. A new cluster of hepatitis A infection in hemophiliacs traced to a contaminated plasma pool. J Med Virol 1999;57:91-9.

5. Syed NA, Hearing SD, Shaw IS, et al. Outbreak of hepatitis A in the injecting drug user and homeless populations in Bristol: Control by a targeted vaccination programme and possible parenteral transmission. Eur J Gastroenterol Hepatol 2003;15:901-6.

6. Hutin YJ, Sabin KM, Hutwagner LC, et al. Multiple modes of hepatitis A virus transmission among methamphetamine users. Am J Epidemiol 2000;152:186-92.

7. Chuang CS, Tung SY, Lee IL, et al. Clinical features and outcome of chronic viral hepatitis with acute exacerbation in patients with concurrent infections of hepatitis B and C virus. Dig Dis Sci 2008;53:511-6.

8. Tepper ML, Gully PR. Hepatitis B. CMAJ 1997;156:1033-4.

9. Roy E, Alary M, Morissette C, et al; SurvUDI Working Group. High hepatitis $\mathrm{C}$ virus prevalence and incidence among Canadian intravenous drug users. Int J STD AIDS 2007;18:23-7.

10. Zou S, Forrester L, Giulivi A. Hepatitis C update. Can J Public Health 2003;94:127-9. estimate of the true burden of hepatitis suprainfection as a result of misclassification.

Despite these limitations, the data highlight the value of timely public health follow-up. In BC, public health follow-up is performed at the local level and may be dependent on local policies, resources and priorities. Acute HAV and HBV can be prevented through immunization. HAV suprainfection has declined considerably since 1998/1999, when publicly funded HAV vaccine was introduced for persons with HCV and HBV, indicating that BC's immunization policy is effective. However, acute HBV infection after HCV diagnosis continues, despite the introduction of publicly funded HBV vaccine for IDUs (at high risk for HCV) in 1992 and in 1997 for persons with HCV. Vaccination coverage for HBV may be improved among IDU and HCV-reactive persons by comprehensive case follow-up when HCV infection is identified. However, because persons with HCV may not use primary care regularly, health care facilities frequented by this vulnerable population can be targeted and immunization status assessed at all health care encounters.

11. Patrick DM, Buxton JA, Bigham M, Mathias RG. Public health and hepatitis C. Can J Public Health 2000;91(Suppl 1):S18-S23.

12. Fiore AE, Wasley A, Bell BP; Advisory Committee on Immunization Practices (ACIP). Prevention of hepatitis A through active or passive immunization: Recommendations of the Advisory Committee on Immunization Practices (ACIP). MMWR Recomm Rep 2006;55(RR-7):1-23.

13. Koff RS. Risks associated with hepatitis A and hepatitis B in patients with hepatitis C. J Clin Gastroenterol 2001;33:20-6.

14. Zarski JP, Bohn B, Bastie A, et al. Characteristics of patients with dual infection by hepatitis $B$ and $C$ viruses. J Hepatol 1998;28:27-33.

15. Sagnelli E, Coppola N, Scolastico C, Mogavero AR, Filippini P, Piccinino F. HCV genotype and "silent" HBV coinfection: Two main risk factors for a more severe liver disease. J Med Virol 2001;64:350-5.

16. Kiefer LA, Honish A, Predy G, Talbot JA. The seroprevalence of hepatitis $\mathrm{A}$ and $\mathrm{B}$ in people testing positive for hepatitis $\mathrm{C}$. CMAJ 2000;162:207-8.

17. Ochnio JJ, Scheifele DW, Marion SA, et al. Participant-collected, mail-delivered oral fluid specimens can replace traditional serosurveys: A demonstration-of-feasibility survey of hepatitis A virus-specific antibodies in adults. Can J Public Health 2007;98:37-40.

18. Uhlmann S, Buxton JA. A provincial and territorial review of hepatitis A in men who have sex with men. Can Commun Dis Rep 2007;33:1-11.

19. Daly P. Hepatitis $C$ and the British Columbia experience with hepatitis A vaccination. J Viral Hepat 2000;7(Suppl 1):23-5. 
20. Pollock SL, Sheikholeslami A, Edgar B, David ST, Buxton JA. The changing epidemiology of hepatitis A in British Columbia: Using health authority follow-up data to inform policy and practice. Can Commun Dis Rep 2006;32:239-44.

20. Patrick DM, Tyndall MW, Cornelisse PG, et al. Incidence of hepatitis $\mathrm{C}$ virus infection among injection drug users during an outbreak of HIV infection. CMAJ 2001;165:889-95.

22. Wood E, Kerr T, Stoltz, et al. Prevalence and correlates of hepatitis C infection among users of North America's first medically supervised safer injection facility. Public Health 2005;119:1111-5.

23. Mast EE, Weinbaum CM, Fiore AE, et al; Advisory Committee on Immunization Practices (ACIP) Centers for Disease Control and Prevention (CDC). A comprehensive immunization strategy to eliminate transmission of hepatitis B virus infection in the United States: Recommendations of the advisory committee on immunization practices (ACIP) part II: Immunization of adults. MMWR Recomm Rep 2006;55(RR-16):1-33.
24. Patrick DM, Bigham M, Ng H, White R, Tweed A, Skowronski DM. Elimination of acute hepatitis B among adolescents after one decade of an immunization program targeting grade 6 students. Pediatr Infect Dis J 2003;22:874-7.

25. Jayaraman GC, Lee B, Singh AE, Preiksaitis JK. Trends in testing behaviours for hepatitis $C$ virus infection and associated determinants: Results from population-based laboratory surveillance in Alberta, Canada (1998-2001). J Viral Hepat 2007;14:249-54.

26. O'Toole TP, Pollini R, Gray P, Jones T, Bigelow G, Ford DE. Factors identifying high-frequency and low-frequency health service utilization among substance-using adults. J Subst Abuse Treat 2007;33:51-9.

27. Buxton JA, Kim JH. Hepatitis A and hepatitis B vaccination responses in persons with chronic hepatitis $\mathrm{C}$ infections: A review of the evidence and current recommendations. Can J Infect Dis Med Microbiol 2008;19:197-202. 


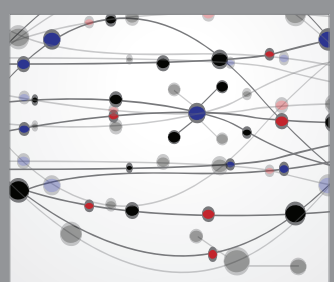

The Scientific World Journal
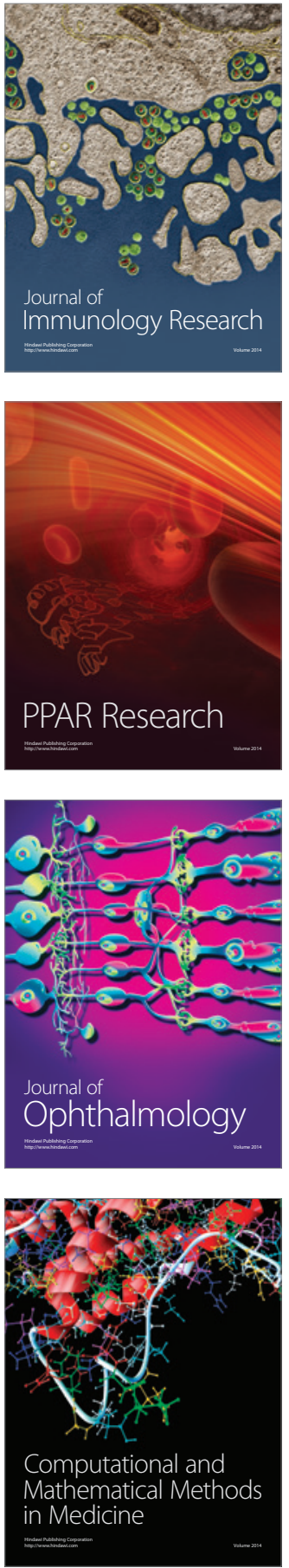

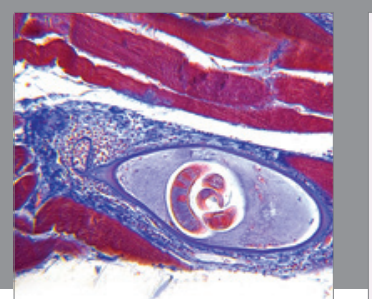

Gastroenterology Research and Practice

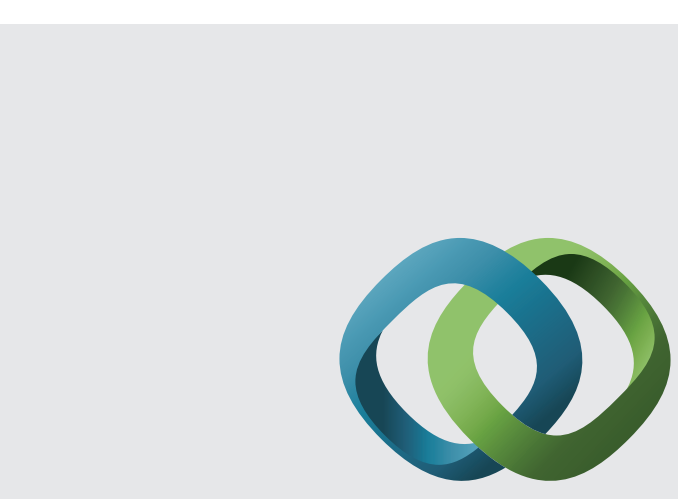

\section{Hindawi}

Submit your manuscripts at

http://www.hindawi.com
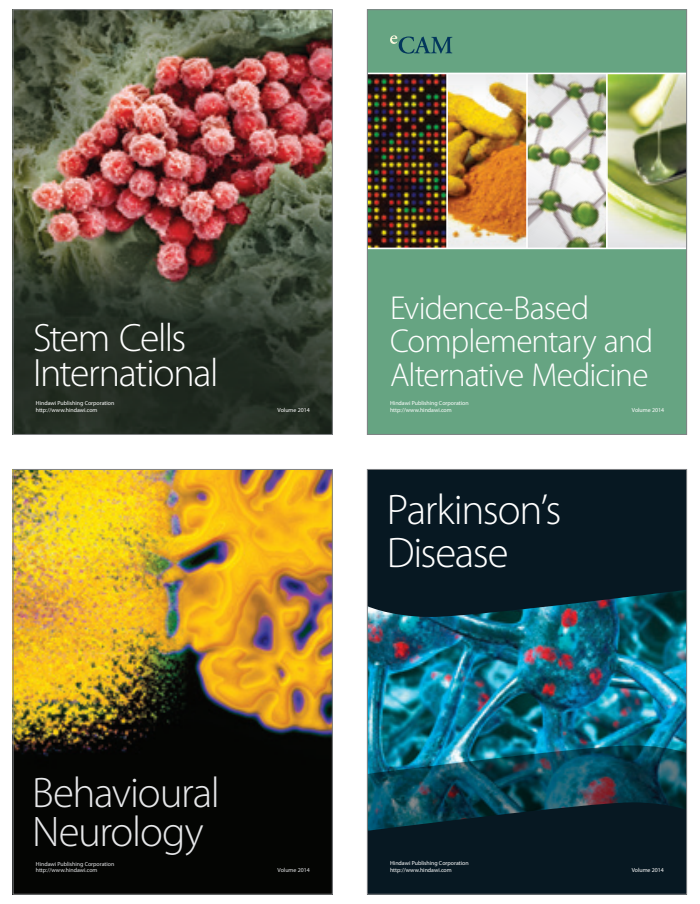
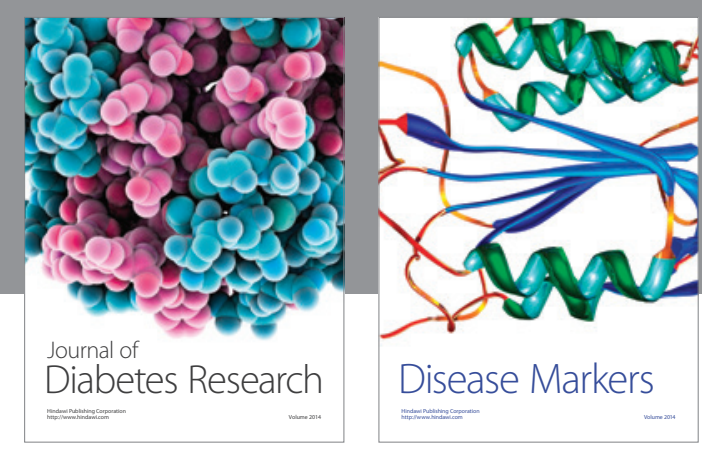

Disease Markers
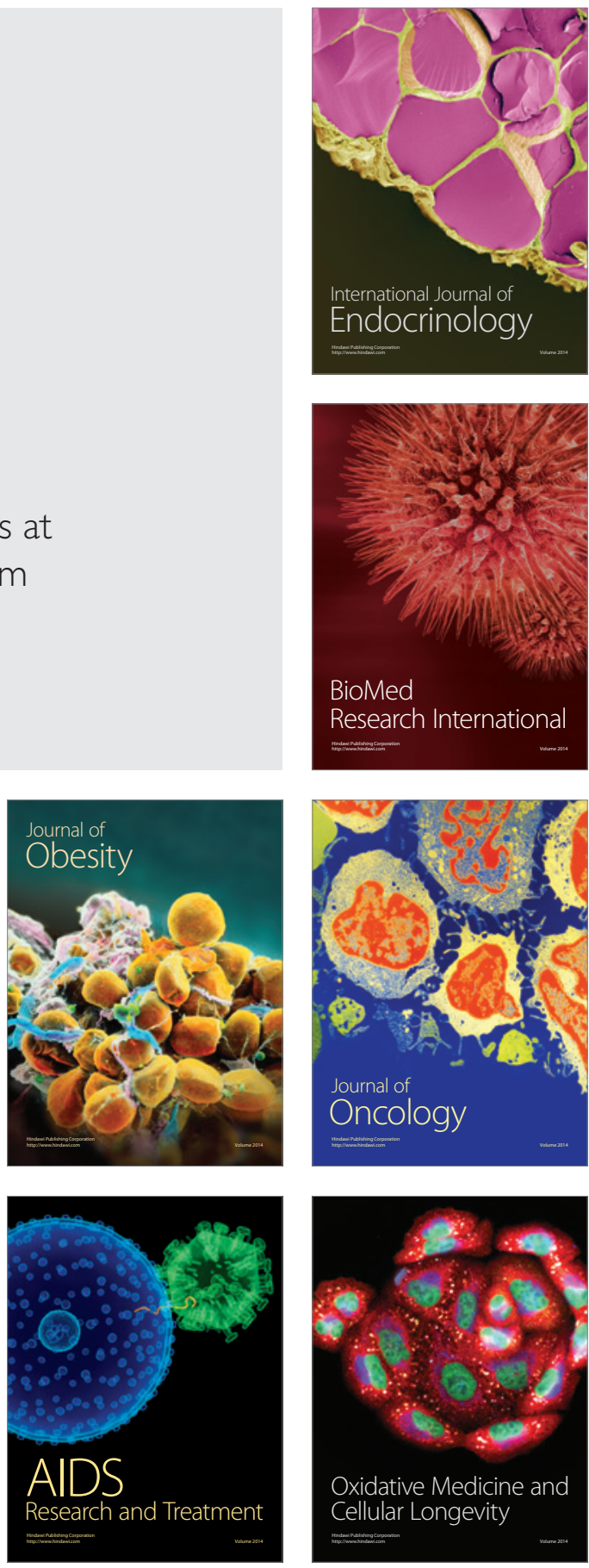